ГРНТИ 71.37.75

DOI: $10.14451 / 1.185 .70$

JEL код: Z18

\title{
ВЪЕЗДНОЙ ТУРИЗМ КАК ПРИОРИТЕТ ГОСУДАРСТВЕННОЙ ПОЛИТИКИ В РЕСПУБЛИКЕ КАЗАХСТАН
}

\author{
(c) 2020 Купешова Сауле Тулеухановна \\ кандидат экономических наук, старший преподаватель \\ Казахский национальный университет имени аль-Фараби, Казахстан, Алматы \\ Email: s.kupeshova@mail.ru \\ (c) 2020 Айжарықов Самрат Иссаұлы \\ докторант 1-го курса по специальности «Государственное и местное управление» \\ Казахский национальный университет имени аль-Фараби, Казахстан, Алматы \\ Email: aizharykov.samrat@gmail.com
}

Настоящая статья посвящена изучению особенностей въездного туризма как приоритета государственной политики в Республике Казахстан, выявлению достижений в данной области, определению сохраняющихся проблем и разработке рекомендаций по совершенствованию системы развития въездного туризма в стране. В научной литературе проблематика въездного туризма исследуется комплексно и системно, положения зарубежных и казахстанских авторов обобщены и проанализированы в настоящей статье, изучены основы законодательства Казахстана по развитию туризма, учтены статистические показатели и позиции экспертов. Все это стало основой разработки предложений по дальнейшему совершенствованию предпринимаемых государством мер по увеличению внешнего туристического потока. В исследовании применены следующие методы: контент-анализа, сравнительный и системный анализ, индукцию и дедукцию, обобщение, а также статистический анализ, прогнозирование развития въездного туризма Казахстана с учетом применения разработанных нами рекомендаций. В статье показано, что сегодня в Казахстане превалирует внутренний туризм, а въездной туризм, к сожалению, находится на невысоком уровне развития, уступая показателям ведущих стран на мировом туристическом рынке. Вместе с тем для развития въездного туризма в Казахстане существуют все необходимые предпосылки, и страна имеет большой потенциал в этом секторе экономики. Мы выявили основные проблемы на пути повышения уровня въездного туризма в Казахстане и разработали ряд рекомендаций. Прежде всего, на наш взгляд, следует сформировать в Казахстане полноценный туристический кластер, который объединит в себе усилия государства, бизнеса, гражданского общества и СМИ для решения общей задачи формирования благоприятного туристического имиджа страны и, как следствия, увеличения въездного туризма. Считаем важным развивать необходимую инфраструктуру, применять современные технологии в работе с клиентами, развивать онлайн-туризм, применять персонифицированный подход при работе с клиентами, проводить политику, повышающую лояльность клиентов. Необходимо обеспечить обучение и переподготовку кадров, которые сегодня должны обладать высокой квалификацией и уметь работать в социальных сетях Интернета, применяя актуальные и эффективные маркетинговые стратегии, полезно расширить и углубить международное сотрудничество с государствами, в которых туристическая деятельность более развита, чем в Казахстане. Проведенное в статье исследование имеет высокую теоретическую значимость, т.к. может применяться при обучении будущих специалистов в сфере туризма. Практическая ценность исследования также не вызывает сомнений, поскольку его результаты могут применить органы государственной власти Казахстана в процессе совершенствования политики развития въездного туризма и законодательства Республики Казахстан.

Ключевые слова: Республика Казахстан, въездной туризм, государственное регулирование, туристическая статистика, перспективы развития въездного туризма. 


\section{Введение.}

Изучение особенностей въездного туризма как приоритет государственной политики в Республике Казахстан довольно актуально в настоящее время, поскольку в стране на экспертном уровне часто обсуждается данный вопрос. Вместе с тем конкуренты Казахстана часто имеют более развитую инфраструктуру и высокий уровень сервиса при низких ценах, что привлекает иностранных туристов. Более того, в странах с развитой туристической отраслью работают высококвалифицированные кадры, способные применять передовые технологии при работе с клиентами, обеспечивая последним персонифицированные услуги по реализации туристических туров. Представляется, что Казахстан сегодня не может полностью раскрыть свой туристический потенциал вследствие отсутствия у него полноценного туристического кластера, в котором объединились бы органы государственной власти, деловые круги, СМИ и гражданское общество. При этом о Казахстане как о туристическом центре за рубежом мало информации, не сформирован и не продвигается соответствующий благоприятный международный имидж. Несмотря на обилие научных трудов, посвященных изучению проблем развития въездного туризма, вышеуказанные вопросы в литературе мало освещены. Казахстану сегодня необходимы современные высокотехнологичные подходы к развитию въездного туризма и применение успешного зарубежного опыта. Данные малоизученные вопросы составили наш исследовательский интерес. Объектом исследования являются общественные отношения, связанные с развитием туризма в Казахстане, предметом исследования - въездной туризм как приоритет государственной политики в Республике Казахстан. Актуальность темы нашего исследования обусловлена большим туристическим потенциалом Казахстана, который пока не раскрыт, упускаемыми в этом отношении возможностями для государства и населения, а также недостатком внимания отечественных и иностранных ученых к данной проблеме в Казахстане, а также высокой теоретической и практической значимостью результатов такого исследования, поскольку они могут быть учтены при обучении будущих специалистов и в работе органов государственной власти. Целью исследования стала разработка рекомендаций по совершенствованию мер, направленных на раз- витие въездного туризма в Республике Казахстан. Задачами исследования являются изучение теоретико-методологических основ данной проблематики, анализ статистических данных и принимаемых в стране мер по развитию въездного туризма, а также разработка рекомендаций по улучшению ситуации в рассматриваемой области. Методы исследования: контент-анализа, сравнительный и системный анализ, индукция и дедукция, обобщение, статистический анализ, прогнозирование развития въездного туризма Казахстана с учетом применения разработанных нами рекомендаций. Выдвинутая нами гипотеза полностью подтвердилась. в Казахстане сегодня недостаточно развит въездной туризм, поскольку упускаются из виду многие возможности, которые могли бы позволить стране осуществлять это значительно быстрее. Увеличить поток иностранных туристов в Казахстан можно посредством формирования в стране полноценного туристического кластера как это уже сделано в большинстве развитых стран мира. Следует также развивать инфраструктуру, формировать и продвигать положительный международный имидж Казахстана для привлечения туристов, применять современные технологии, осуществлять обмен опытом с государствами, где туристический сервис находится на более высоком уровне, осуществлять подготовку и переподготовку высококвалифицированных кадров, развивать онлайн туризм. Разработанные нами рекомендации имеют большое теоретическое и практическое значение и могут быть применены органами государственной власти в своей работе и использоваться как материалы для подготовки в вузах будущих высококвалифицированных специалистов в области туризма.

Обзор литературы. Туризм активно развивается на протяжении многих веков, по мере создания необходимой инфраструктуры и распространения в мире научно-технического прогресса возрастает и количество людей, желающих посещать разные страны. В настоящее время известно много разных видов туризма: культурно-познавательный, спортивный, приключенческий, деловой, медицинский, экологический, конгрессно-выставочный, сельский, религиозный и т.д. Туризм приносит принимающим странам высокие доходы в бюджет, именно поэтому туристическую деятельность стремятся развивать не только государства, куда люди со всего мира едут к морю отдыхать, но и страны, 
не имеющие подходящих климатических условий, однако способные показать другие преимущества отдыха у них туристов. Это и повлияло на большое современное разнообразие видов туризма. Научный интерес к изучению туризма также имеет давнюю историю. Ученые стремятся оценить туристический потенциал тех или иных стран, выявить их конкурентные преимущества, проанализировать систему государственного регулирования данной отрасли экономики, представить статистику, выявить тенденции на мировом рынке, сделать прогнозы на будущее и т.д. В частности, Лью А. и Маккерчер Б. в своей работе «Моделирование туристических движений: анализ местного назначения» (Лью, 2006) провели исследование траекторий перемещения людей в мире в туристических целях в разные периоды времени, построили действующую и перспективные модели, позволяющие сделать расчеты туристических потоков в зависимости от разных переменных условий. Р. МеринероРодригес и Дж.И.Пулидо-Фернандес в своей статье «Анализ отношений в туризме: обзор» обратили внимание на особенности международного сотрудничества государств в сфере туризма, выявили группы наиболее активных в этом отношении стран и показали преимущества, которые они из этого извлекают на мировом рынке туристических услуг (Меринеро-Родригес, 2016). Дж. И.Л.Мигенс и Дж. Ф.Ф.Мендес в работе «Путешествия и туризм: сложная сетевая структура» (Мигенс, 2008) приводят определения понятий «путешествие» и «туризм», выявляют сходства и различия этих терминов, анализируют профильные международные нормативноправовые акты, двусторонние соглашения государств, исследуют условия, необходимые для активного развития туризма во всех регионах мира, указывают, что глобализация во многом способствует данному процессу, поскольку обеспечивает взаимозависимость национальных экономик и позволяет формировать целые туристические кластеры. Л.Дуайер и П.Форсайт в работе «Оценка преимуществ и недостатков въездного туризма» проводят глубокий анализ особенностей развития государствами въездного туризма, оценивают выгоды и риски, связанные с политикой привлечения в страну постоянного потока туристов. Они приходят к выводу о том, что, несмотря на сопутствующие издержки, связанные с организацией приема потока туристов из других стран, созданием необходимой инфраструктуры и развитием высоких технологий, выгоды государства от развития въездного туризма довольно высоки, поэтому следует его активно поддерживать на уровне государственного управления (Дуайер, 1993). С. Казануева, А. Гальего и М.Р. Гарсиа-Санчесв статье «Анализ социальных сетей в туризме» выявили большое значение использования современных социальных сетей в виртуальном пространстве для продвижения туристических услуг, они указали на стремительное развитие онлайн-туризма и необходимость привлечения высокий технологий в данную отрасль (Казануева, 2016). В этом отношении интересна также работа Ф.Батисты, С. Марио и А. Марин «Анализ пространственновременных моделей туризма в Европе с высоким разрешением с применением традиционных данных и big data», в ней авторы пишут о масштабных возможностях использования разных баз данных для привлечения в страну путешественников и развития въездного туризма (Батиста, 2018). Культурологические аспекты туризмы представлены, в частности, в статье В.А.Ли «Культурологический анализ въездного туризма Китая». Там описывается культурная политика Китая, связанная с регулированием потока мигрантов (Ли, 2007). Ч. Вьетце в статье «Культурное влияние на въездной туризм в США: гравитационный подход» обращает внимание на то, что культурное разнообразие страны становится весьма аттрактивным фактором для развития въездного туризма, по мнению автора, следует ставить на этом акцент при формировании международного имиджа государства. К аналогичному выводу пришли ученые И.Х.Хванг, У. Гретцель и Д. Р. Фезенмайер «Стандарты Multi City: туристы в США» (Хванг, 2006). Проблемам развития въездного туризма посвящены также исследования Х.К. Вуа и Г.Лия «Изучение поведения въездных туристов в Гонконг с использованием фотографий с геотегами» (Вуа, 2015) и Дж. Ву, Х.Ванг и Б.Пан «Агентное моделирование сети въездного туризма в Китае» (Ву, 2019). При этом авторы данных работ подчеркивают влияние современных технологий на привлечение в страны туристов, указывают на необходимость индивидуального подхода к работе с клиентами и персонификации разрабатываемых для них предложений. В целом можно сделать вывод о том, что проблематика развития въездного туризма в странах мира является весьма актуальной в научных исследованиях. Вместе с 
тем, на наш взгляд, уделяется недостаточно внимания сегодня развитию въездного туризма в Республике Казахстан, поэтому далее сконцентрируемся на изучении данного вопроса.

Методология. Материалами исследования послужили научные работы отечественных и зарубежных авторов по вопросам развития въездного туризма в Республике Казахстан и его совершенствования, нормативно-правовые акты PK, выступления официальных лиц, статистические данные в сфере казахстанского туризма, новостные материалы СМИ, оценки экспертов. Bсе это позволило применить в статье качественные и количественные показатели, обеспечить достоверность результатов исследований. В процессе работы мы опирались на следующие методы исследования: контент-анализа, сравнительный и системный анализ, индукцию и дедукцию, обобщение, а также статистический анализ, прогнозирование развития въездного туризма Казахстана с учетом применения разработанных нами рекомендаций. Мы сформулировали следующие исследовательские вопросы: 1) Какова степень изученности в научной литературе проблемы развития въездного туризма; 2) Каким образом государство в настоящее время поддерживает туристическую отрасль экономики, и какие основные проблемы существуют в Казахстане; 3) Какой полезный зарубежный опыт следует перенять Казахстану в сфере развития въездного туризма? 4) Какие меры следует предпринять государству, чтобы повысить темпы развития въездного туризма? В своем исследовании мы сформулировали следующую гипотезу: в Казахстане сегодня недостаточно развит въездной туризм, поскольку упускаются из виду многие возможности, которые могли бы позволить стране осуществлять это значительно быстрее. Увеличить поток иностранных туристов в Казахстан можно посредством формирования в стране полноценного туристического кластера как это уже сделано в большинстве развитых стран мира. Следует также развивать инфраструктуру, формировать и продвигать положительный международный имидж Казахстана для привлечения туристов, применять современные технологии, осуществлять обмен опытом с государствами, где туристический сервис находится на более высоком уровне, осуществлять подготовку и переподготовку высококвалифицированных кадров, развивать онлайн туризм. Отметим, что результаты проведенного нами исследования полностью подтвердили данную гипотезу.

Результаты и обсуждение. Международный туризм в настоящее время является одной из наиболее быстро развивающихся отраслей внешнеэкономической деятельности. Рост влияния туризма на мировую экономику является одной из наиболее значительных и давних тенденций, которая сопровождает становление и развитие мировой экономики. В рамках стратегического плана развития Казахстана до 2025 г. (Стратегический план, 2018), туризм стал одним из приоритетных направлений развития национальной экономики. Основной целью развития международного туризма в Казахстане является создание современного, эффективного и конкурентоспособного туристического комплекса, на основе которого будут созданы условия для развития дальнейшего международного сотрудничества в сфере туризма. Международный туризм является ценным источником дохода для поддержки бюджета страны. Он играет важную роль в экономическом развитии страны. Большое количество людей, которые посещают страну, стимулируют производство товаров и услуг.

В истории античного мира первые путешествия в область современного Казахстана были связаны с глобальным туристическим объектом - Великим шелковым путем, формирование которого началось в третьем тысячелетии до нашей эры. Первые туристические места в Казахстане были связаны с завоеванием и переселением турецких племен. Первым организатором паломнического туризма в Казахстане был Тимур. Памятные места, связанные с его именем, на протяжении многих лет, помогли реализовать различные социальные формы туризма. Главный памятник был создан в 1399 г. по приказу Тимура. Он был мусульманином и построил гробницу А.Яссави. Сегодня у Казахстана есть все основания для привлечения как иностранных, так и местных инвесторов в индустрию туризма, что в значительной степени способствует созданию совместных предприятий. По мнению Т.П.Притворовой и Е.Ж.Абзалбека Казахстан должен больше работать над маркетингом, рекламой в Европе, Америке, Азии и других странах. Примерно через десять лет страна может стать одним из ведущих туристических направлений. Кроме того, казахи - гостеприимные люди, улыбчивые, открытые, дружелюбные, что располагает туристов к посещению страны 
(Притворова, 2019: 37).

Туристический продукт Казахстана богат и разнообразен и предоставляет уникальную возможность для развития практически всех видов туризма, от познавательных посещений до культурных и исторических, а также других альтернативных форм туризма и экотуризма. В стране около 100 водных клиник и более 9000 археологических и исторических памятников. Охота и рыбалка, в том числе национальные виды охоты, пользуются популярностью у туристов. Соответственно, Казахстан должен развиваться как туристическое направление, чтобы удовлетворить потребности мирового туристического спроса и привлечь больше туристов. Туризм в Республике Казахстан является приоритетной отраслью. Основной целью развития туризма в Казахстане является создание условий для современного, высокоэффективного и конкурентоспособного туристического комплекса, направленного на развитие отрасли как потенциально успешной местной экономики. В поддержку интеграции страны в мировой туристический рынок и развития ее дальнейшего международного сотрудничества в сфере туризма Правительство Казахстана стало с 2003 г. предпринимать серьезные шаги в развитии туризма. В то время была разработана и реализована программа развития туризма на 2003-2005 гг. После этого была принята Программа развития туризма в Республике Казахстан на 2007-2011 гг., целью которой является развитие конкурентоспособной индустрии туризма для повышения занятости, а также устойчивый рост государственных доходов за счет увеличения объема въездного и внутреннего туризма (Петренко, 2019: 2679).

Казахстан имеет обширную территорию, он географически выгодно расположен в плане развития торговли между Европой и Азией, обладает богатым культурно-историческим наследием, бережно хранит национальные традиции, иными словами, у страны есть все основания активно развивать въездной туризм. В 2016 г. валовая добавленная стоимость (ВДС) туристской отрасли была равна 791,6 млрд. тенге, что на 49,2\% больше, чем в 2015 г. В период 20132016 гг. ВДС туризма увеличился до 217,4\%. В конце 2017 г. доля туризма в ВВП РК равнялась 0,6\%. Для сравнения, в 2014 г. вклад туризма в ВВП Турции составил $10,9 \%$, в ВВП ОАЭ данный показатель достиг 14,3\%. Вместе с тем в 2017 г. количество занятых в отрасли снизилось в два раза и составило 35,4 тыс. чел. (в 2016 г. в туризме было занято 70,8 тыс. чел.). По итогам 2017 г. объем произведенной продукции и оказанных услуг в сфере туризма увеличился на $12,1 \%$ и был равен 226505,4 млн. тенге. Реализация продукции и оказание услуг в данной отрасли увеличился за год на 3,5\% и составил в 2017 г. 212820 млн. тенге. Выездной туризм в Республики Казахстан сегодня преобладает над другими видами туризма. Количество выезжающих на отдых людей из Казахстана превышает количество приезжающих в страну путешественников в 1,8 раз (Рей, 2019: 296).

В Республике Казахстан в 2018 г. был отмечен рост туризма из ОАЭ (50\%), Индии (49\%), Малайзии (44\%), Гонконга (22\%), Польши (16\%), Южной Кореи (15\%), США (5,8\%). В 2018 г. Казахстан посетили около 8,49 млн. человек, что на 10,2 процента больше, чем в предыдущем году (The Astana Times, 2019). В своем обращении к нации от 5 октября 2018 г. «Растущее благосостояние граждан Казахстана: повышение доходов и качества жизни» президент Казахстана Н.А.Назарбаев (Официальный сайт Президента РК, 2018) поручил правительству разработать государственную программу развития туризма. В результате в ноябре 2019 г. была принята Государственная программа развития туристской отрасли Республики Казахстан на 2019-2025 годы. По мнению Н.А.Назарбаева, программа позволит систематически продвигать Казахстан как новое туристическое направление на мировой туристической карте, что повысить показатели въездного туризма. (Официальный информационный ресурс Премьер-Министра Республики Казахстан, 2019).

Казахский туризм должен иметь международный бренд и привлечь к многостороннему сотрудничеству общественные объединения, инициативных граждан, местные исполнительные органы, бизнес, Национальную палату предпринимателей и министерства культуры и спорта Казахстана, иностранных дел, информации и коммуникаций к развитию туризма. По словам председателя Национальной туристической компании Казахстана Р. Кузембаева, продвижение туризма, в первую очередь, ориентировано на демографические когорты поколения Y и Z, которые часто определяют современные тенденции в сфере путешествий на цифровых платформах. Далее в стратегии продвижения основное внимание уделяется рекламе ключе- 
вых туристических продуктов. Стратегия также предполагает работу с высокопотенциальными рынками и целевыми странами. Приоритетными для продвижения туристическими районами являются озера Алаколь и Балхаш, Алматинские горы, курортные зоны Баянаул, Имантау-Шалкар и Щучинск-Боровое, а также Мангистауская и Туркестанская области (The Astana Times, 2019).

В 2018 г. состоялся визит популярных китайских блогеров с более чем 100 миллионами подписчиков. Они посетили туристические направления в Астане, Шучинско-Боровской курортной зоне, Алматинской и Алматинской, ВосточноКазахстанской и Туркестанской областях. Их посты прочитали более 150 миллионов читателей. Казахстанский певец Д. Кудайберген стал первым послом по туризму в национальной компании, к нему недавно присоединились бывшие космонавты А.Арцебарский, Ю.Батурин, Ю.Маленченко и Т. Мусабаев. В июле 2018 г. они посетили озеро Алаколь, вспомнили то время, когда были на реабилитации после полета в курортной зоне. Дополнительные казахстанские туристические инициативы включают в себя подготовку Туристической карты Казахстана совместно с Министерством культуры и спорта Казахстана и региональными акиматами (администрациями), поддержку участия казахстанского бизнеса в международных туристических выставках и проведение экспедиций по всей стране.

Вместе с тем в настоящее время, несмотря на предпринимаемые в государстве усилия, ученые отмечают, что, с точки зрения доступности, уровня качества услуг и ценовой политики, туристический сервис Казахстана недостаточно конкурентоспособен на мировом рынке по сравнению с другими государствами (Жидкоблинова, 2013: 1080). Более того, в Казахстане в настоящее время существует проблема, препятствующая развитию въездного туризма, это отсутствие широкого спектра анимационных мероприятий. Для того, чтобы создать и предложить эти виды деятельности, необходима подготовка специалистов из-за рубежа, поскольку в Казахстане отсутствует соответствующий опыт. Кроме того, отсутствие подходящих мест для развлечений в ключевых точках туристических зон препятствует развитию массового въездного туризма. В результате в туризме преобладают одноразовые и однодневные поездки, когда значительное количество времени уходит на дорогу. Такие поездки скучны и оставляют плохие воспоминания у большинства путешественников. Другой проблемой, которую следует учитывать, является тот факт, что из-за мирового финансового кризиса местные инвесторы не вкладывают средства в строительство новых туристических объектов. Более того, в Казахстане недостаточно развит онлайн-туризм, не разработаны маркетинговые стратегии продвижения туристических продуктов под индивидуальные запросы путешественников с учетом передовых технологий взаимодействия с потенциальными клиентами в социальных сетях Интернета, что позволило бы повысить их лояльность, сделать постоянными туристами (Оспанов, 2012: 3).

Серьезные системные проблемы в сфере туризма существуют в Казахстане давно и должны быть адресованы всем уровням власти. В настоящее время следует сосредоточиться на решении следующих основных проблем, которые препятствуют развитию въездного туризма в Казахстане:

- Высокие цены на все виды транспорта, гостиничные и ресторанные услуги. Кроме того, высокая стоимость транспортных услуг, в первую очередь для рейсов, увеличивает стоимость туристического продукта Казахстана, что снижает его конкурентоспособность на мировом рынке;

- Слабый государственный контроль в сфере туризма. После отмены деятельности по лицензированию туристических агентств, их мониторинг становится более сложным. Это приводит к произволу и отсутствию контроля со стороны многих туристических агентств;

- Низкий уровень развития транспортной и гостиничной инфраструктуры. На этом уровне развития инфраструктуры цены значительно завышены, чтобы обеспечить большую прибыль от небольшого числа туристов;

- Слабая исследовательская база для изучения туризма. Отсутствуют статистические данные, которые можно было бы использовать для комплексного прогнозирования, долгосрочного планирования и организации туризма для каждой территории путешественников;

- Отсутствие профессиональной и научной подготовки в сфере туризма. Существует лишь небольшое количество грамотных гидов, способных вносить весомый вклад в развитие туризма в стране по современным высокотехнологичным требованиям;

- Несовершенство законодательных и эко- 
номических стимулов для въездного туризма на государственном и местном уровне;

- Недостаточная организация туристических услуг, что создает негативный имидж для отдельных туристических направлений и страны в целом;

- Отсутствие целенаправленной политики государства и местных властей по формированию положительного имиджа страны как привлекательного туристического направления;

- Узкий спектр предлагаемых туристических услуг, несмотря на большой потенциал;

- Отсутствие комплексной и успешной маркетинговой стратегии для продвижения въездного туризма.

Полагаем, что решение выше указанных проблем позволит во многом повысить уровень развития въездного туризма в Казахстане. Полагаем также, что государству следует принять специальные программы обучения и переподготовки кадров в сфере туризма. В этих целях полезны международные обмены специалистами и более активное сотрудничество с другими странами, где туризм развит на высоком уровне. Необходимо формировать в Республике Казахстан полноценный туристический кластер, в работе которого примут участие органы государственной власти, деловое сообщество, общественные объединения, инициативные граждане, СМИ и все заинтересованные организации и физические лица.

\section{Заключение.}

В данном исследовании мы проанализировали особенности въездного туризма как приоритета государственной политики в Республике Казахстан. Мы выявили историческую туристи- ческую привлекательность Казахстана, определили основные меры, которые принимает государство для регулирования туризма в стране, показали достижения Казахстана в последние годы в привлечении иностранных туристов, раскрыли основные современные проблемы в отрасли и предложили пути их решения для улучшения ситуации. Индустрия туризма является прибыльной экономической деятельностью. Как показывает мировой опыт, для развития туризма необходимо объединить усилия всех заинтересованных сторон туристического рынка, как в частном, так и в государственном секторе. В связи с этим одним из приоритетных направлений казахстанской экономики должно стать развитие гостиничного хозяйства с упором на создание туристических кластеров. Туристические кластеры могут помочь предприятиям улучшить предлагаемые туристам услуги и справиться с международной конкуренцией. С другой стороны, роль органов власти Республики Казахстан заключается в улучшении инфраструктуры, а также в планировании и координации политики развития туризма на уровне страны и регионов. Необходимо формировать туристический кластер в Казахстане, который объединит усилия государства, предпринимателей, гражданского общества и СМИ. Результаты нашего исследования имеют высокую теоретическую и практическую ценность - их можно применить в целях обучения будущих специалистов в сфере туристического бизнеса, а также в работе органов государственной власти по совершенствованию системы управления данной отраслью национальной экономики.

\section{Библиографический список}

1. Batista, F., Mario S., Marín, A. Analysing spatiotemporal patterns of tourism in Europe at high-resolution with conventional and big data sources. Tourism Management. Vol. 68, October 2018, 101-115 pp.

2. Casanueva, C., Gallego, À., Garcìa-Sànchez, M.-R. Social network analysis in tourism. Current Issues in Tourism 19, 1190-1209 (2016).

3. Dwyer, L., Forsyth, P. Assessing the benefits and costs of inbound tourism. Annals of Tourism Research, Vol. 20, Issue 4, 1993, 751-768 pp.

4. Hwang, Y.-H., Gretzel, U., Fesenmaier, D.R. Multicity trip patterns: Tourists to the United States. Annals of Tourism Research 33, 2006, 1057-1078 pp.

5. Lew, A., McKercher, B. Modeling tourist movements: A local destination analysis. Annals of Tourism Research 33, 2006. 403-423 pp.

6. $L i, W$. A cultural analysis of the inbound travelers in China. Journal of Guangxi University for Nationalities (Philosophy and Social Sciences Edition) 1, 2007. 140-144 pp.

7. Merinero-Rodriguez, R., Pulido-Fernandez, J.I. Analysing relationships in tourism: A review. Tourism Management 54, 2016, 122-135 pp. 
8. Miguèns, J.I.L., Mendes, J.F.F. Travel and tourism: Into a complex network. Physica A 387, 2008. 2963-2971 pp.

9. Ospanov G. M. Tourism in the republic of Kazakhstan: current state and prospects of the development international Journal of experimental education. 2012. No 12.26.

10. Vietze, Ch. Cultural Effects on Inbound Tourism into the USA: A Gravity Approach. Tourism Economics 18, 2008. 2231-2247 pp.

11. Vua, H.Q., Lia, G. Exploring the travel behaviors of inbound tourists to Hong Kong using geotagged photos. Tourism Management, Vol. 46, February 2015, 222-232 pp.

12. Wu, J., Wang, X., Pan, B. Agent-based simulations of China inbound tourism network. Scientific Reports, Vol. 9, 2019, 743-756 pp.

13. Zhidkoblinova, O.V. State Policy of Tourism Industry Development in the Republic of Kazakhstan. Karaganda Economic University of Kazpotrebsoyuz, Karaganda, Kazakhstan World Applied Sciences Journal. 2013. 23 (8): 1079-1084.

14. Zhussupova D. Inbound tourism to Kazakhstan increased 10 percent in 2018 over previous year. The Astana Times, 27.02.2019. [Electronic resource] URL: https://astanatimes.com/2019/02/inbound-tourism-to-kazakhstanincreased-10-percent-in-2018-over-previous-year/ (дата обращения: 24.04.2020).

15. Государственная программа развития туристской отрасли Республики Казахстан на 2019-2025 годы // Официальный информационный ресурс Премьер-Министра Республики Казахстан. 28.11.2019. [Электронный pecypc]. URL: https://primeminister.kz/ru/gosprogrammy/gosudarstvennaya-programma-razvitiya-turistskoyotrasli-respubliki-kazahstan-na-2019-2025-gody (дата обращения: 24.04.2020).

16. Послание Президента Республики Казахстан Н.А.Назарбаева народу Казахстана. // Официальный сайт Президента PK. 05.10.2018. [Электронный ресурс]. URL: https://www.akorda.kz/ru/addresses/addresses_of_ president/poslanie-prezidenta-respubliki-kazahstan-nnazarbaeva-narodu-kazahstana-5-oktyabrya-2018-g (дата обращения: 24.04.2020).

17. Петренко Е.С., Даулетова А. М., Мажитова С. К., Шабалтина Л. В. Анализ мер государственной поддержки по развитию туризма в Республике Казахстан // Экономические отношения. 2019. Том 9 № 4. С. 2677-2692.

18. Притворова Т.П., Абзалбек Е. Ж. Постиндустриальные услуги в Казахстане: оценка динамики и структуры в контексте мировых тенденций // Экономика. 2019. № 1. С. 35-52.

19. Рей И.Ю., Жансагимова А.Е. Анализ развития туризма в Республике Казахстан // Большая Евразия: Развитие, безопасность, сотрудничество. 2019. № 2-1. С. 296-298. URL: https://cyberleninka.ru/article/n/analizrazvitiya-turizma-v-respublike-kazahstan-1 (дата обращения: 27.04.2020).

20. Стратегический план развития Республики Казахстан до 2025 года был утвержден Указом Президента Республики Казахстан № 636 от 15 февраля 2018 года // Официальный сайт Президента Республики Казахстан [Электронный ресурс]. URL: http://www.akorda.kz/ru/legal_acts/ob-utverzhdenii-strategicheskogo-planarazvitiya-respubliki-kazahstan-do-2025-goda-i-priznanii-utrativshimi-silu-nekotoryh-ukazov-prezidenta (дата обращения: 24.04.2020). 